\title{
Optimization of MFA parameters for harrowing crops with simultaneous fertilization
}

\author{
Alexander Serguntsov ${ }^{1, *}$, and Leonid Alekseenko ${ }^{2}$ \\ ${ }^{1}$ Chair of processes and machines in agribusiness, Kuban State Agrarian University named after \\ I.T.Trubilin, 350044 Krasnodar, Russia \\ ${ }^{2}$ Faculty of mechanization, Kuban State Agrarian University named after I.T.Trubilin, 350044 \\ Krasnodar, Russia
}

\begin{abstract}
The calculation of the energy intensity of the harrowing process of winter crops with simultaneous fertilization is theoretically justified by drawing up a flowchart with a step-by-step calculation of the parameters and operating modes of a multifunctional unit. The flowchart shows the parameters and operating modes that are set and that need to be calculated to achieve the goal of calculating energy intensity. In the course of calculations, we constructed the dependence of energy consumption on the operating speed, that is, we determined the minimum energy consumption at maximum power when using a multifunctional unit.
\end{abstract}

\section{Material and methods of research}

The research of operations is one of the methods for making an optimal decision, the purpose of which is to justify the number of decisions made. The best solution is called optimal, in turn, the solution is the possibility of choosing controlled actions, which is noted in the textbook Burda A. G. [1]. Our task is to optimize the operating modes, as well as the parameters of a multifunctional unit for crop harrowing with simultaneous application of mineral fertilizers and their embedding in the soil. In order to find the optimal solution, it is necessary to use a systematic approach to solving and analyzing this problem. The research of operations consists of a certain number of stages [1]: 1) problem statement; 2) creation of a mathematical model; 3) solution of the problem; 4) implementation in practice.

\section{Results of research}

When constructing a mathematical model, a task is set, which is performed in verbal form by setting the goal and condition of the problem, it can be expressed using the objective function and the optimization criterion.

The objective function is a formula for the numerical calculation of the optimality criterion. After solving the problem, they are expressed by the same number.

\footnotetext{
*Corresponding author: sasha2008_9191@mail.ru
} 
The optimization criterion is the quality factor by which the system options are selected and it should be adjusted by quantitative measurement.

Our task is to determine the design parameters of the MFU (the shape of teeth of the disk; the diameter of the disk of the harrow-hoe $(m)$, the weight $(t)$, the distance between the disks in a row $(\mathrm{m})$, the capacity of the fertilizer hopper $\left(\mathrm{m}^{3}\right)$, the width of the grip $(\mathrm{m})$.

Operating parameters: specific resistance of the machine and the unit $(k N)$, required power $(k W t)$, specific costs of total energy for the working process of the MFU $(M J / h a)$, productivity of the MFU $(\mathrm{ha} / \mathrm{h})$, depth of tillage $(\mathrm{m})$, working speed $(\mathrm{km} / \mathrm{h})$, rate of fertilizer consumption $(\mathrm{kg} / \mathrm{ha})$, fuel consumption $(\mathrm{kg} / \mathrm{ha})$.

In this construction of the problem, the unknown parameters are: volume of the fertilizer hopper, productivity, working speed of the unit, specific costs of total energy, specific and total traction resistance, mass, fuel consumption, width of the grip of the unit [2].

The goal of our task is to solve these parameters using the optimization criterion - a minimum of specific energy costs for performing the production process of harrowing winter wheat crops with simultaneous fertilization with solid mineral fertilizers.

The specified numerical restrictions applied in the problem: width of the grip - no more than $20 \mathrm{~m}$, capacity of the fertilizer tank - no more than $0.9 \mathrm{~m}^{3}$, working speed of the unit is no more than $20 \mathrm{~km} / \mathrm{h}$, permissible traction force - $14 \mathrm{kN}$, length of the rut - no more than $1500 \mathrm{~m}$, engine power according to the brand of the power unit - 58.2 kWt (MTZ-80 tractor), fertilizer application rate - no more than $5 \mathrm{t} / \mathrm{ha}$.

The second equally important stage is the construction of a mathematical model. When constructing the task of the modeling process, it is necessary to clarify the list of its characteristics and analyze the relationships of the main parameters. All characteristics should reflect the essence of the modeled process, as well as be amenable to numerical measurement, but in order not to make our development of the mathematical model difficult, not to lose its essence in the details and minutiae. At the same time, do not forget the rule of R. Bellman, American mathematician - "do not oversimplify and do not overcomplicate"

In indicator of a system or process is a certain value that characterizes a particular state or property, showing the essence or basis of the modeled process. In mathematics, a parameter is a value which value is expressed as a constant numeric value and stored throughout the solution of the problem.

The model was created and recorded in the form of a structure. In his work Burda A. G. noted that when constructing a mathematical model of the task, it is necessary to build a scheme or a special table in which all the regime, technological, constructive, as well as other conditions and requirements are expressed in the form of a system of inequalities and equations, all of them are combined by the objective function. The sequence of developing a mathematical model: first enter a system of variables, then write a system of constraints, and then - a target function.

The main indicators of the variable model include: $V_{a g}$ - working gripping width of the unit, m; $V_{\mathrm{ag}}=1 \div 20 ; V_{r}$ - working speed of movement $i$ of the unit, $\mathrm{km} / \mathrm{h} ; V_{p}=1 \div 20$; $V_{b}$ - capacity of fertilizer hopper, $\mathrm{m}^{3} ; V_{b}=0,5 \div 0,9 ; L_{r}$ - working length of gut, $\mathrm{m}$; $L_{r}=500 \div 1500$. Model constants are known constants.

The constant constants of the model are known:

$G_{t r}$ - tractor engine's mass, т $\left(G_{t r}=3,85 \mathrm{t}\right) ; E_{f}$ - energetic coefficient of fuel $e_{d t}, \mathrm{MJ} / 1 ;$; $N_{e}$-rated power of the tractor engine, $\mathrm{kWt}$ (in our problem, the MTZ-80 tractor is adopted, which has $\left.N_{e}=58.2 \mathrm{~kW}\right) ; T_{G_{t r}}-$ annual load of tractor engine, h, $\left(T_{G_{t r}}=1095 \mathrm{~h}\right)$; $\eta_{u}$-tractive effort utilization factor for harrowing $\left(\eta_{u}=0,9\right) ; T_{G_{s h m}}-$ annual load of unit's loading, h, $\left(T_{G_{s h m}}=180 \mathrm{~h}\right) . V_{a g}=1 \div 20 \mathrm{~m}$, (step 1$) ; V_{r}=1 \div 20 \mathrm{~km} / \mathrm{h}($ step 1$) ;\left(\eta_{u}=0,9\right)$; $V_{b}=0,5 \div 0,9 \mathrm{~m}^{3}$ (step 0,2$)$. 
Restrictions are imposed on all the main variables: $B_{a g}, V_{r}, V_{b}, L_{r}$.

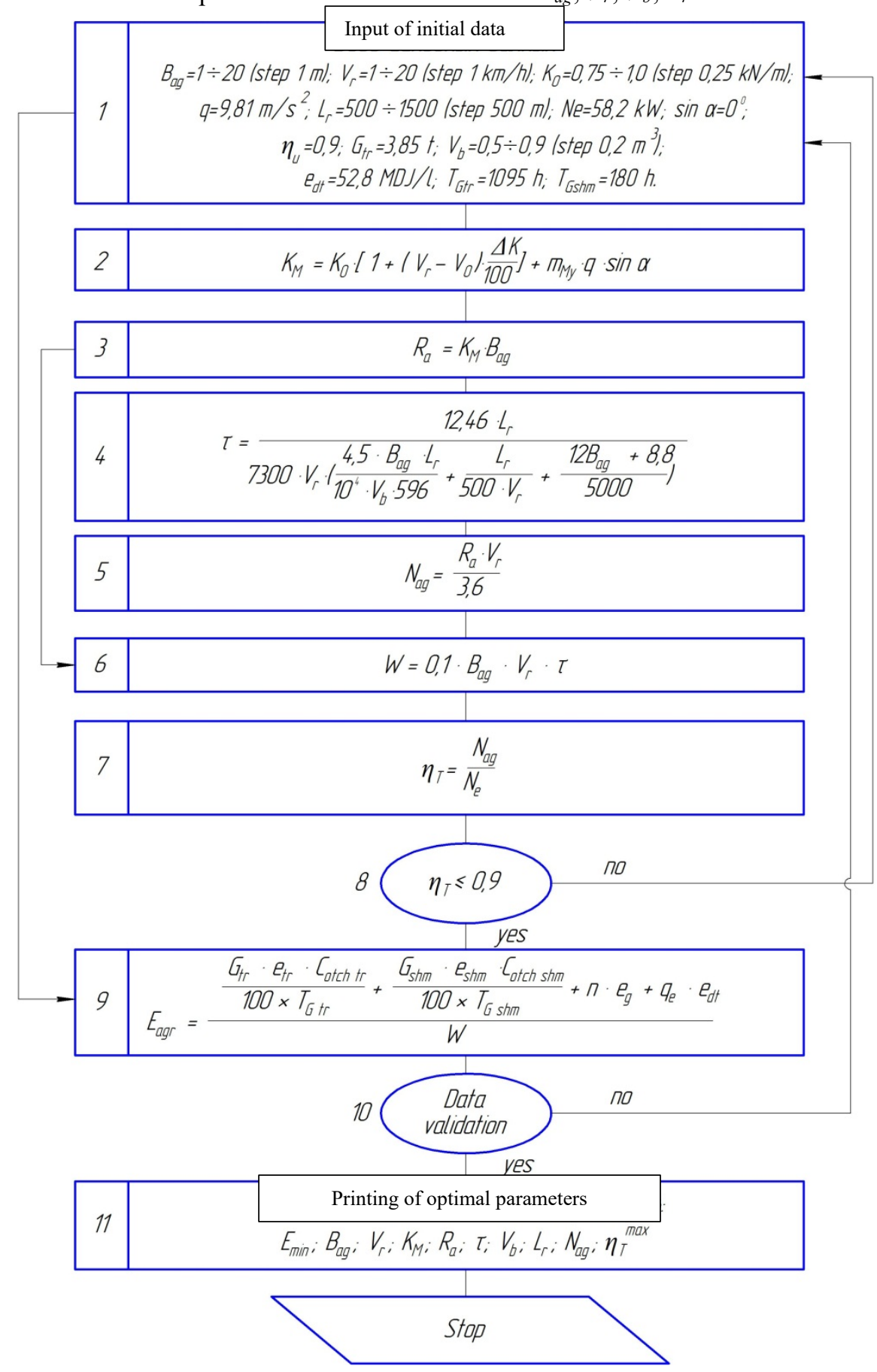

Fig. 1. Flowchart of the algorithm of parameters and operating modes of the MFU for crop harrowing with simultaneous additional fertilizing

When constructing the objective function and modeling the direct costs of total energy, we used auxiliary constraints. Since the minimum specific fuel consumption $(\mathrm{kg} / \mathrm{kWh})$ for 
each tractor transmission is different, it is therefore necessary to set the speed range when the consumption will be minimum (see Figure 1 the flowchart of the algorithm for optimizing the parameters and operating modes of our MFU operator No. 9) [3].

$q$ - acceleration of free fall, $\mathrm{m} / \mathrm{s}^{2}$ and MFU modes for crop harrowing with simultaneous additional fertilizing $\left(q=9.81 \mathrm{~m} / \mathrm{s}^{2}\right)$;

$\Delta K$ - rate of increase in the specific resistance of the unit depending on the speed of movement of the unit, \%;

$m_{M y}-$ specific mass of mounted machine, $\mathrm{t} / \mathrm{m} ;\left(m_{M y}=0,150-0,250 \mathrm{t} / \mathrm{m}\right)$;

$K_{o}$ - coefficient of specific resistance of the unit at a speed of $5 \mathrm{~km} / \mathrm{h}$ and a processing depth of $5 \mathrm{~cm}, \mathrm{kN} / \mathrm{m}\left(K_{o}=1.0 \mathrm{kN} / \mathrm{m}\right)$;

$\sin \alpha$ - sine of the elevation angle of the terrain, $\alpha$ degree $\left(\alpha=0^{\circ}\right)$.

The sequence of records in the structural form of a mathematical model [4].

In our problem, we do not know the main variables, the working speed of movement $\left(V_{r}\right)$, at what site's size $(L r)$ the unit will work most efficiently with minimal total energy consumption for the production process of winter crop harrowing with simultaneous application of mineral fertilizers, the capacity of the fertilizer hopper $(V b)$, what should be the optimal width of the grip of the unit ( Vag). The objective function of the model (Eagr) after the transformations is written in the arithmetic operator No. 9 of the flowchart of the algorithm (Fig. 1):

$$
E_{a g r}=\frac{\frac{G_{t r} \cdot e_{t r} \cdot C_{o t c h}}{100 \cdot T_{G_{t r}}}+\frac{G_{s h m} \cdot e_{s h m} \cdot C_{o t c h s h m}}{100 \cdot T_{G_{s h m}}}+n \cdot e_{g}+e_{d t} \cdot q_{e}}{W} \rightarrow \min ,
$$
$\mathrm{MJ} / \mathrm{ha}$;

where $E_{\text {arp }}$ - specific total energy consumption for the developed production process,

$$
\begin{gathered}
W \text { - hourly efficiency of the MFU, ha/h; } \\
G_{t r} \text { - mass of the tractor engine, } \mathrm{kg} ; \\
G_{s h m} \text { - mass of the agricultural machine, } \mathrm{kg} ;
\end{gathered}
$$

$e_{m p}$ and $e_{c x м}$ - energy equivalents for the production and operation, respectively, of a tractor engine and a rotary harrow with a mineral fertilizer spreader, $\mathrm{MJ} / \mathrm{kg}$, $\left(e_{t r}=86,4 \mathrm{MJ} / \mathrm{kg}, e_{\text {shm }}=75 \mathrm{MJ} / \mathrm{kg}\right)$;

$C_{\text {otch } h_{t r}}$ и $C_{\text {otch } h_{s h m}}$ - deductions for depreciation, repair and storage, respectively, of tractors and agricultural machinery, \%; $\left(C_{\text {otch }}=26,3 \%, C_{\text {otch }_{s h m}}=28,2 \%\right)$;

$T_{G_{t r}}$ и $T_{G_{s h m}}$ - standard annual load, respectively, of the tractor engine and agricultural machinery, $\left(T_{G_{t r}}=1095 \mathrm{ч}, T_{G_{s h m}}=180 \mathrm{ч}\right)$;

$n$ - number of mechanical engineers, persons;

$e_{g}$ - energetic equivalent of living labor costs, MJ/per.-h, $\left(e_{g}=43,4 \mathrm{MJ} /\right.$ per.-h);

$q_{e}$ - hourly fuel consumption during the production process, $1 / \mathrm{h}$;

$e_{d t}$ - energetic equivalent of fuel, $\mathrm{MJ} / 1,\left(e_{d t}=52,8 \mathrm{MJ} / \mathrm{l}\right)$;

$\tau$ - coefficient of use of the working time of the shift during the operation of the given unit, which is determined by the formula derived by us (operator No. 4, Fig. 1) [5]:

$$
\tau=\frac{12,46 L_{p}}{7300 \cdot V_{p} \cdot\left(\frac{4,5 \cdot B_{a 2} L_{p}}{10^{4} \cdot V_{\sigma} \cdot 596}+\frac{L_{p}}{500 \cdot V_{p}}+\frac{12 B_{a z}+8,8}{5000}\right)},
$$


After performing the calculations according to the flowchart shown in Fig. 1, the dependence of the energy consumption of the unit on the speed of movement was constructed in Fig. 2.

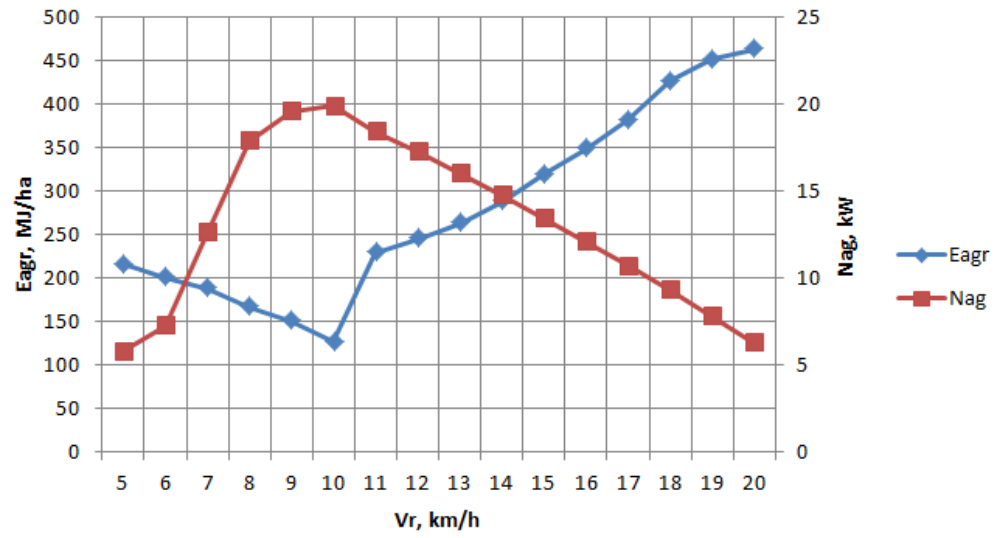

Fig. 2. Dependence of energy intensity of the $E_{a g r}$ and power of the $N_{a g}$ on the operating speed of the $V_{r}$.

Operator No. 11, after all the calculations performed, prints the optimal parameters of the MFU [6]: working speed of the movement $V_{r}$, coefficient of specific resistance of the unit $K_{M}$, minimum of the target function $E_{a g r}$, coefficient of total resistance $R_{a}$, width of the grip of the unit, coefficient $\tau$, optimal length of the rut $L_{r}$, capacity of the hopper $V_{b}$, the traction power $\mathrm{Nag}$, calculated gears of the tractor, as well as the maximum value of the efficiency of the unit. These parameters will be optimal [7].

\section{Conclusion}

The optimal parameters of $V_{a g}, V_{b}$ and operating modes of the proposed MFU are justified by the solution of the developed mathematical model according to the criterion of optimization of the minimum total energy costs for performing the process of early spring harrowing of winter wheat crops with simultaneous additional fertilizing $(188.5 \mathrm{MJ} / \mathrm{ha})$, width of the unit $-6.7 \mathrm{~m}$, diameter of the disk working body $-518 \mathrm{~mm}$, capacity of the fertilizer hopper $-0.7 \mathrm{~m}^{3}$, working speed of the unit $-6.43 \mathrm{~km} / \mathrm{h}$, power of the tractor engine $-58.2 \mathrm{~kW}$.

\section{References}

1. Burda, A. G. Research of operations in economics of AIC: manual [Text] / A. G. Burda, G. P. Burda. Kuban State Agrarian University. - Krasnodar, 2004 - 566 p.

2. Serguntsov A. Optimization of parameters and operating modes of the rotary working body for harrowing agricultural crops / A. Serguntsov, V. Serguntsova // E3S Web of Conferences. 2020. - Vol. 193. - P. 01021.

3. Zhuk A. F. Search for the type and justification of the parameters of combined working bodies for pre-sowing processing [Text]: Thesis of $\mathrm{PhD}$ in Engineering. Moscow, 1978. - $238 \mathrm{p}$.

4. Konovalov V. Analytical study of the design parameters of the grinding unit of disk harrows / Konovalov V., Konovalov S., Igumnova V. // B сборнике: IOP Conference 
Series: Earth and Environmental Science. 12th International Scientific Conference on Agricultural Machinery Industry, INTERAGROMASH 2019. 2019. P. 012086.

5. Konovalov, V.I. Justification of design parameters of a disk working body with a changing radius of curvature / Konovalov, V.I. // E3S Web of Conferences. - 2020. Volume193. - P. 01014.

6. Belousov, S.V. Mathematical processing of experimental data of the agricultural working body / Belousov, S.V., Belousova, A.I. // IOP Conference Series: Materials Science and Engineering, 2020, 971(5), 052059

7. Serguntsov A.S. Optimization of harrowing processes of winter wheat crops with simultaneous additional fertilizing [Text]: Thesis of PhD in Engineering. - Krasnodar, 2020. $-152 \mathrm{p}$. 